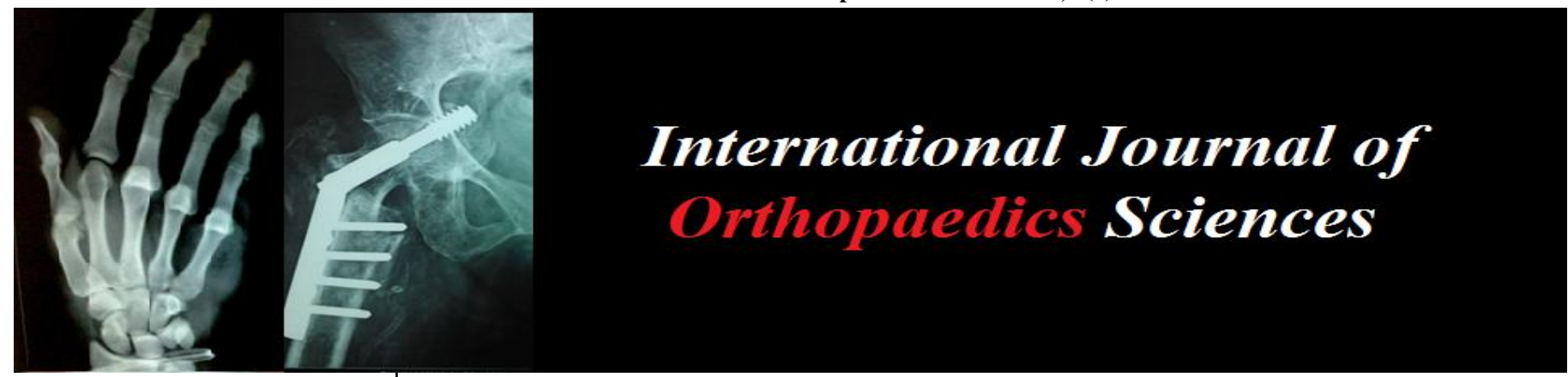

ISSN: $2395-1958$

IJOS 2018; 4(3): 677-681

(C) 2018 IJOS

www.orthopaper.com

Received: 20-05-2018

Accepted: 21-06-2018

\section{Chethan BA}

Junior Resident

Adichunchanagiri Institute of

Medical Sciences, BG Nagara,

Mandya, Karnataka, India

\section{Deepak}

Associate Professor

Adichunchanagiri Institute of Medical Sciences, BG Nagara,

Mandya, Karnataka, India

\section{KG Gunnaiah}

Professor, Dept of Orthopaedics Adichunchanagiri Institute of Medical Sciences, BG Nagara, Mandya, Karnataka, India

\section{Correspondence}

Chethan BA

Junior Resident

Adichunchanagiri Institute of

Medical Sciences, BG Nagara,

Mandya, Karnataka, India

\section{A clinical study of neglected idiopathic CTEV managed by ligamentotaxis using Joshi's external stabilising system}

\author{
Chethan BA, CD Deepak and KG Gunnaiah
}

DOI: https://doi.org/10.22271/ortho.2018.v4.i31.120

\begin{abstract}
Congenital Talipes Equino Varus is the commonest deformity of the foot and affects males 10:7 more often than females. The incidence worldwide is 1-2 per 1000 live births. Although most cases are sporadic occurrences, families have been reported with clubfoot as an autosomal dominant trait with incomplete penetrance.

Aims and objectives: This study was conducted with the aim of evaluating the efficacy of the controlled differential fractional distraction with Joshi's External Stabilisation System (JESS) as a method of treatment in resistant clubfeet and the morbidity and complications of the technique and to suggest ways to overcome them.

Methodology: The prospective study was done in a tertiary care center involving subjects with old, recurrent and resistant cases of clubfoot deformities treated by Joshi's external stabilizing system.

Results: All the cases were evaluated clinically, radiologically both before and after correction. The cosmetic and functional improvement is satisfactory, bony radiological correction comparable, and the ankle movements especially dorsiflexion better than that produced by open surgery.

Conclusion: Correction by an external fixator is a useful method for the management of clubfoot in neglected and resistant cases.
\end{abstract}

Keywords: Clubfoot, jess, neglected, relapsed, external fixator

\section{Introduction}

Idiopathic clubfoot is of the oldest and commonest congenital deformity of mankind, ever since man has adopted the erect posture. Neglected clubfoot usually presents the unyielding rigid deformities because of the extremely contracted skin, tendons, ligaments and capsules on the postero medial aspect of the foot. Remodeling of the tarsal bones in the deformed position usually results in altered shape, which has an effect on the unpredictable results of treatment in such feet. It occurs in variable severity and some of the mobile feet are corrected well with manipulation and stretching ${ }^{[2]}$. $30 \%$ to $50 \%$ of clubfeet will not respond to conservative treatment and will require surgery ${ }^{[3,4]}$.

The discovery of principles of distraction histoneogenesis by Ilizarov was a breakthrough in managing complex deformities of limbs ${ }^{[5,7]}$. However, application of Ilizarov technique was complicated due to its bulky nature and complicated management ${ }^{[8]}$.

Joshi (1988) developed a lighter and simpler version of the same technique which could be easily applied to smaller feet ${ }^{[9]}$.

Principle: Differential Fractional Distraction Histiogenesis.

The basic principle of external fixation in this study was the same as that advocated by Ilizarov where in physiological tension and stress applied to the tissue stimulates histogenesis of tissues, while controlled differential distraction gradually corrects the deformities and realigns the bones ${ }^{[10]}$.

Dr. B.B. Joshi of Bombay has modified the Ilizarov method by simple wires and simple distracters. This fixator ${ }^{[11,12]}$ has many theoretical advantages like avoiding fibrous tissue formation, prevents crushing of the tissues on the convex side as against the bony procedures and proper control of all components of corrections, with actual lengthening and histioneogenesis of the soft tissues and ultimately leading to plantigrade foot. 
Suresh et al. studied the difference between Ilizarov technique and JESS method and found that the wires in JESS fixators were pre-stressed and not-tensioned, preventing the chance of cutting through bone and soft tissue. Also, the procedure of JESS fixator is less costing and simple when compared to Ilizarov technique. Overall, they reported JESS fixators are superior in comparison to Ilizarov fixator, especially in older children with neglected clubfeet ${ }^{[11]}$.

\section{Materials and methods}

This observational study was conducted on all the patients with late presentation of CTEV since March 2016 to December 2017 at Adichunchanagiri Institute of Medical Sciences, B G Nagara. The study included 12 patients with old, recurrent and resistant cases of clubfoot deformities treated by Joshi's external stabilizing system.

All patients included in this study were thoroughly assessed clinically and radiologically. In the radiological assessments, measurements of various angles were done in AP and lateral view in stress dorsiflexion in all cases. $\mathrm{X}$ rays were studied for talocalcaneal angle, talo-first metatarsal angle (all in AP view), talocalcaneal angle and Tibiocalcaneal angle (all in lateral view). Pirani scoring system was used in this study to assess the severity of deformity and to assess the correction achieved after final casting as shown in Table 1.

Procedure: We operated all our patients under general anaesthesia. The procedure involved two major stepsinsertion of $\mathrm{K}$ - wires and creation of hold and connection between the hold ${ }^{[9]}$.

Insertion of K-wires Tibial K-wire placement: Two parallel transfixing wires were passed in the tibia about $2.5 \mathrm{cms}$ below and lateral to the tibial tuberosity, perpendicular to the longitudinal axis from lateral to medial. The length of the middle segment of the Z' bar was marked below the first wire. The second wire was passed parallel to the first wire at this level.

Calcaneal K-wire placement: Two parallel K-wire were passed through the tuber of calcaneum from medial to lateral side taking care that they were well away from the course of the neurovascular structures on the medial side. One additional half pin K-wire was passed from the posterior aspect of the calcaneum along the long axis. The entry point was below the insertion of the tendo-achilles in the midline using distractor as the guide.

Metatarsal K-wire placement: One transfixing K-wire was passed through the necks of first and fifth metatarsal from lateral to medial side in such a way that the K-wire engages at least the fifth and the first metatarsals $\mathrm{n}$. Two additional wires were passed parallel to and 10 to $12 \mathrm{~mm}$ apart from either side engaging three metatarsals each so that the third metatarsal has engaging half pins from either side through it.

Creation of Holds and connecting between the holds two ' $Z$ ' bars were attached to the tibial pins, one on either side. The wires were prestressed before the link joints were tightened. Two transverse bars were attached to the ' $Z$ ' rods, one anteriorly and one posteriorly. Calacaneometatarsal distractors were then attached to the $\mathrm{K}$-wires. Two ' $\mathrm{L}$ ' rods were attached to calcaneal $\mathrm{K}$-wires and two other ' $\mathrm{L}$ ' rods were attached to the metatarsal $\mathrm{K}$-wires one on either side with the arms of the ' $L$ ' rods facing posteriorly and inferiorly. One posterior transverse bar was attached to the posterior calcaneal half pin and the posterior arms of the ' $L$ ' rods.
Tibiocalcaneal distractors were applied, one on each side connecting the corresponding transverse rods. Two additional transverse rods were attached to the inferior arms of the ' $L$ ' rods which took the toe sling which provided dynamic traction to prevent flexion contracture of the toes as the deformity was being corrected. All four distractors were distracted till resistance was felt. Extra lengths of the Kwires were cut, and no tension was created in them.

The transverse anterior rod of the tibial hold and metatarsal hold was connected on either side static tibiometatarsal connecting rod. This provided tension force and kept the anterior portion of the joint open. It also prevented crushing of the articular cartilage and provided better glidage to the talus while correcting the equinus.

Adequate skin release was made at the pin entry sites. Haemostasis at the pin entry wounds was achieved with pressure. Dry dressing of the pin entry wounds was done after cleaning. The sharp cut ends of the Kirshner wires were protected. The operative time was on an average one hour.

Distraction Schedule In all hospitalized patients, fractional calcaneo-metatarsal distraction was applied from third postoperative day at the rate of $0.25 \mathrm{~mm} / \mathrm{hrs}$. Differential distraction on medial side was performed twice the rate than that on the lateral side $(0.25 \mathrm{~mm}$ every 6 hours medially and $0.25 \mathrm{~mm}$ every 12 hours laterally). In non-hospitalized patients, parents do the distraction at the rate of $1 \mathrm{~mm} /$ daily on medial side and $1 / 2 \mathrm{~mm} /$ daily on lateral side.

By calcaneo-metatarsal distraction, we achieved correction of forefoot adduction at tarsometatarsal joints, stretching the socket for head of talus and reduction of calcaneocuboid joint. The tibio-calcaneal distraction is carried out in two positions. Initially, the distractors were mounted between the inferior limbs of the ' $Z$ ' rods and posterior limbs of the calcaneal ' $L$ ' rods. The distractors lie parallel to the leg and just posterior to the transfixing calcaneal wires. The distraction was applied at the rate of $0.25 \mathrm{~mm}$ every 6 hours medially and $0.25 \mathrm{~mm}$ every 12 hours laterally and the endpoint was judged clinically. Distraction in this position corrected varus of the hindfoot and equinus. The tibio calcaneal distractors were then shifted posteriorly and connected above to the transverse bar connecting the posterior limbs of ' $Z$ ' rods and below to the posterior calcaneal bars connecting the posterior limbs of ' $L$ ' rods and axial calcaneal pin. The distractors lie on the either side of the axial calcaneal pin. Distraction in this position provided thrust force to stretch posterior structures and corrected hind food equinus at the ankle and subtalar joints. Both distractors were applied at the rate of $0.25 \mathrm{~mm}$ every sixth hourly and the end point assessed clinically and radiologically.

Visual correction of the deformities was noted during the distraction phase. Full correction was achieved, usually at the end of 5 to 6 weeks. X-ray was taken finally after the removal of the fixator. Following the correction, assembly is held in static position for further three to six weeks to allow soft tissue maturation in elongation position. Single stage removal of the whole assembly was done under general anaesthesia. After removal of the assembly, a well moulded below knee plaster cast was applied in maximum correction. The child was allowed to ambulated full weight bearing in the plaster. Later, a short plaster boot was applied which not only acted as an orthotic device but also allowed mobilization of ankle joint and strengthening of tendoachilles. Squatting was encouraged to achieve dorsiflexion of the foot. Plaster was changed for 23 times at an interval of 15 days. 
Results: We managed 12 resistant cases of CTEV. The mean age of the study subjects was 4 years and 9 months. Of the 12 cases, 9 were male and 3 were female. All cases under our study were unilateral resistant clubfeet of which seven were right and five were left.

Equinus at the Ankle: The feet showed well-corrected mobile ankle joints. The post-operative range of motion at the ankle was an average $40^{\circ}$ with $25^{\circ}$ of plantar flexion and $15^{\circ}$ of dorsiflexion.

Fore Foot Adduction: This was assessed clinically and radiologically. The mean precorrection adduction deformity was $28^{\circ}$ and the mean postcorrection abduction achieved was $2^{0}$ in these patients.

Hind foot varus: All patients had a good correction of heel varus. Mean precorrection heel varus was $36^{\circ}$ while mean postcorrection heel varus was $4^{0}$.

Radiological Findings: The talo-calcaneal index was measured both preoperatively and post-operatively. Mean preoperative TC index was 29, improved to 53. All other clinico-radiological parameters were also improved (statistically significant) in all patients. The findings are shown in table 3 .

The overall results were assessed according Pirani Score summarized in Table 1 and George Simons criteria ${ }^{13}$ summarized in Table 2.

The subjects were graded on a scale of good to poor using Pirani Score. A final Pirani score of $0-2$ is regarded as good clinical correction achieved. All patients were reverted to $0-2$ group, that is, good outcome. Before correction the mean Pirani Total score was 5 , which was reduced to 0.5 after the correction, that is, all became more flexible than earlier. By the end of the followup the flexibility of the feet remained unchanged.

According to George Simons criteria they are classified into Satisfactory (Excellent, Good) and Unsatisfactory (Poor). In our series we had 11 satisfactory and one unsatisfactory result. It was common to observe significant edema of the foot during the distraction phase. However, pin-tract infection was noticed in only one case and there were no cases with skin necrosis.

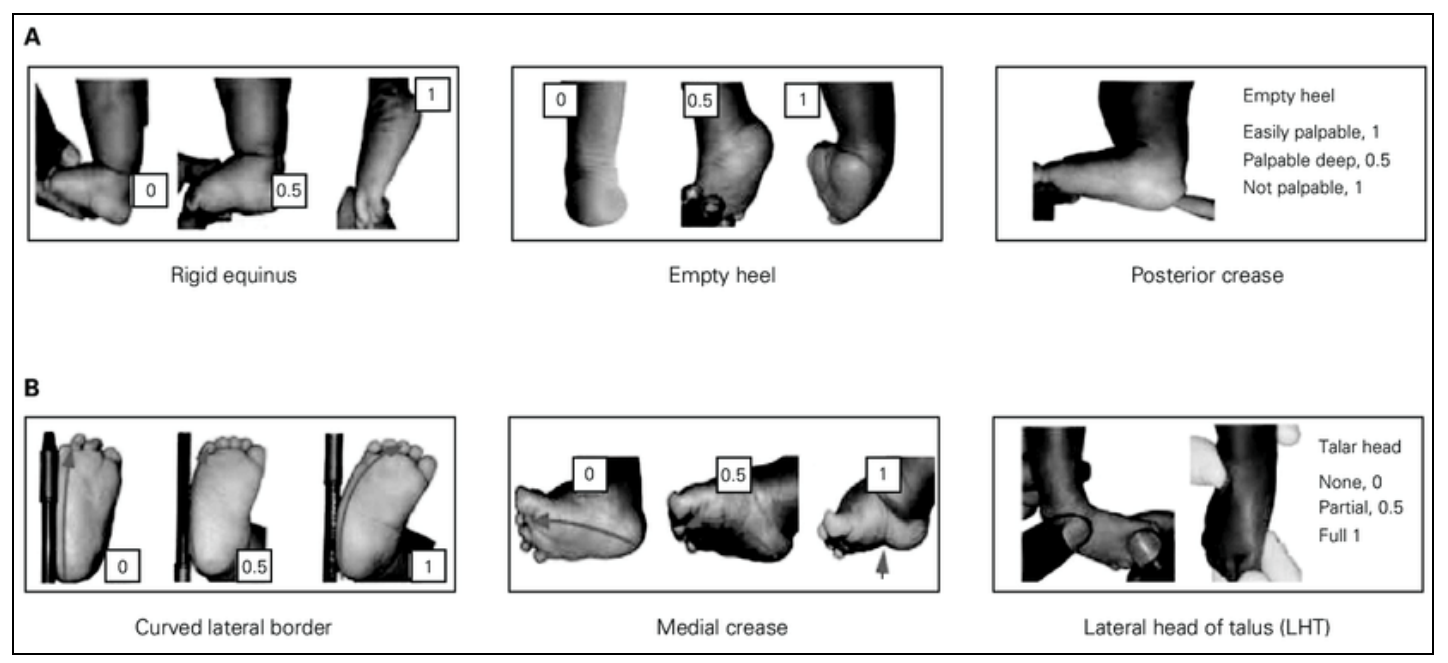

Table 1: Pirani Scoring System

\begin{tabular}{|c|c|c|c|}
\hline Parameters & Normal & Moderate & Severe \\
\hline Midfoot & & & \\
\hline Curved lateral border & 0 & 0.5 & 1 \\
\hline Medial crease & 0 & 0.5 & 1 \\
\hline Talar head coverage & 0 & 0.5 & 1 \\
\hline Hindfoot & & & \\
\hline Posterior crease & 0 & 0.5 & 1 \\
\hline Rigid equinus & 0 & 0.5 & 1 \\
\hline Empty heel & 0 & 0.5 & 1 \\
\hline
\end{tabular}

Table 2: Simons criteria for clinical assessment of outcome of clubfoot surgery

\begin{tabular}{|c|c|c|c|}
\hline No. & Parameters & Satisfactory & Unsatisfactory \\
\hline 1 & Symptoms & None & Minimal to moderate pain with activity \\
\hline 2 & Appearance of hindfoot & Normal to mild deformity & Moderate to significant residual deformity \\
\hline 3 & Forefoot adduction & Mild & Severe \\
\hline 4 & Functional weakness of triceps surae & None or mild & Cannot support weight on toes \\
\hline 5 & Range of motion at ankle & $\begin{array}{c}\text { Dorsiflexion }>10^{0} \\
\text { Plantarflexion }>15^{0}\end{array}$ & $\begin{array}{c}\text { Dorsiflexion }<10^{0} \\
\text { Plantar flexion }<15^{0}\end{array}$ \\
\hline 6 & Range of motion at subtalar joint & Present & Nil \\
\hline 7 & Additional treatment & None, cast, minor surgery & Frequent treatment with cast or major surgery \\
\hline 8 & Complications & Minor & Major \\
\hline
\end{tabular}

Table 3: Radiological findings of the outcome of JESS fixator surgery for resistant clubfeet

\begin{tabular}{|c|c|c|c|}
\hline & Average preop & Average postop & Normal values \\
\hline A.P & $13^{0}$ & $24^{0}$ & $30-35^{0}$ \\
\hline Lateral & $16^{0}$ & $29^{0}$ & $25-50^{0}$ \\
\hline Talocalcaneal Index & $29^{0}$ & $53^{0}$ & $>40^{0}$ \\
\hline
\end{tabular}


Radiographs

Preoperative

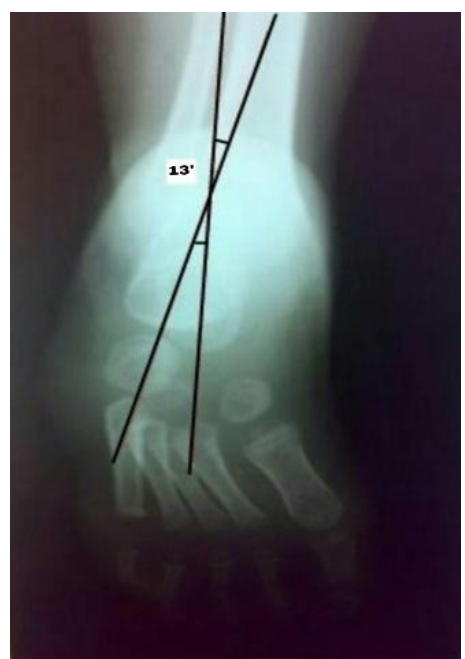

AP view- $13^{0}$

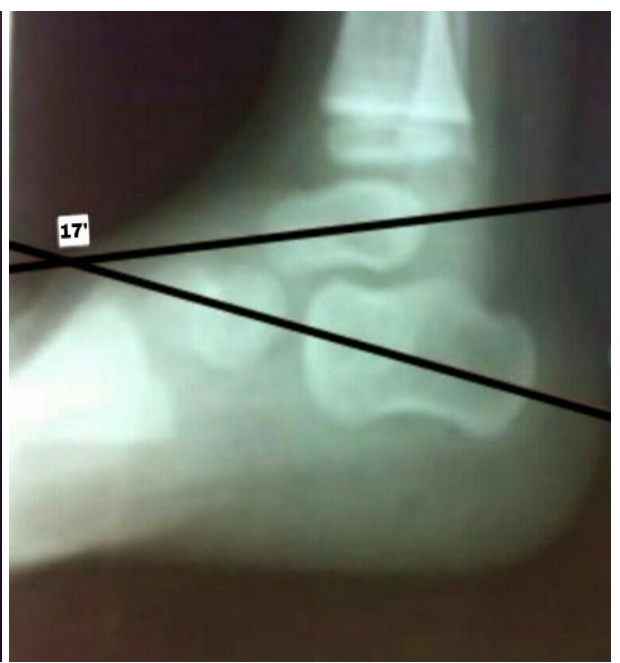

Lateral View-170

TC Index $=30^{\circ}$

\section{Postoperative}

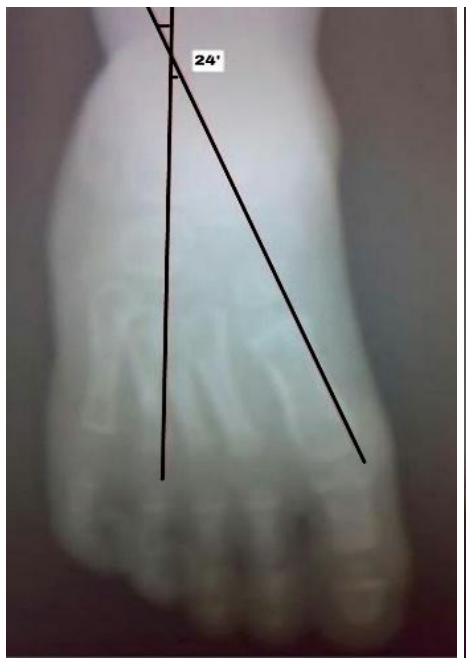

AP view- $24^{0}$

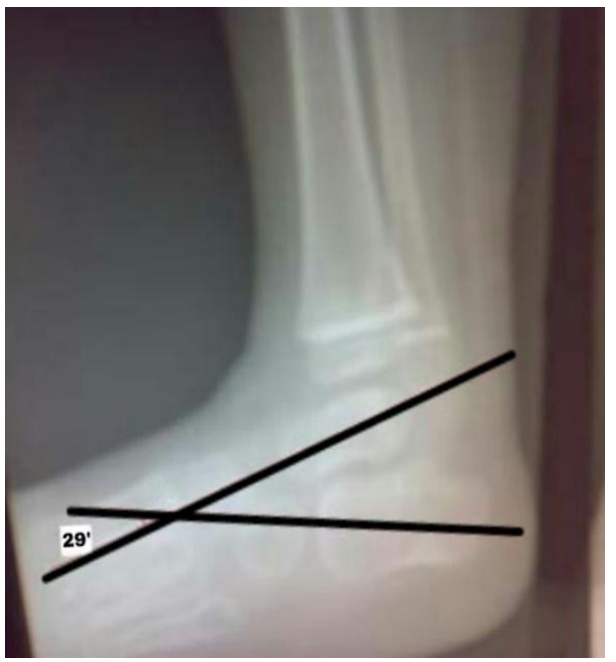

Lateral view- $29^{0}$

TC Index $=53^{0}$

\section{Discussion}

Congenital Talipes Equinovarus is a common paediatric orthopaedic problem, which constitutes a bulk of the congenital anomalies presenting to any paediatric orthopaedic surgeon. Operative options in the club foot deformity treatment are many with nearly the same sort of results. In the absence of universally acceptable grading of the deformity or assessment of the results no two studies can really be compared. Correction by distraction has distinct advantage of histoneogenesis, lack of scar tissue formation and the absence of further shortening of the foot. There are many reports of the fixators distractor correction of clubfoot with variations in the technique with good outcome ${ }^{[6,12]}$. Suresh et al. found JESS to be ideal for correction of residual and relapse clubfoot in their study involving 26 children with 44 clubfeet ${ }^{[11]}$. Similar results were found by Oganesian and Istomina ${ }^{[14]}$. Short-term assessment of results of clubfeet correction with JESS distractor by Anwar and Arun showed excellent and good results in $59.7 \%$ of cases ${ }^{[12]}$.

Suresh et al. studied the difference between Ilizarov technique and JESS method and found that the wires in JESS fixators were pre-stressed and not-tensioned, preventing the chance of cutting through bone and soft tissue. Also, the procedure of JESS fixator is less costing and simple when compared to Ilizarov technique. Overall, they reported JESS fixators are superior in comparison to Ilizarov fixator, especially in older children with neglected clubfeet ${ }^{[11]}$.

Although the follow-up in this series was relatively short (21 months), the results were comparable with the best results in open soft tissue and/or bone surgery.

The better results in the present study can also be attributed to enthusiastic and compliant parents and longer hospitalisation during post-operative period. Anwar and Arun found a strong correlation between better results and children who strictly follow the distraction-static phase protocol and the final outcome, stressing the fact that parent involvement is an essential component in treating neglected clubfeet ${ }^{12}$. A longer period of post-operative stay provided a controlled environment for the static period and reduced the risk of pintract infection and other complication. The evidence from other studies and the present study shows that correction by JESS fixator is a useful method for the management of clubfoot in neglected and resistant cases. 


\section{Conclusion}

JESS modality working on the principle of gradual differential distraction produces better results with less morbidity and low complications rate, than conservative and operative management for the older neglected severely deformed, relapsed, recurrent, and resistant cases. In patients with bony deformities along with soft tissue contractures the JESS fixator has proved to be extremely useful. It is an easy method, which does not require any sophisticated instrumentation and minimal image intensifer. Parents learn the distraction technique easily and comply with the procedure. The cosmetic and functional improvement was satisfactory, bony radiological correction comparable than that produced by open surgery. We may conclude that correction of resistant CTEV by ligamentotaxis using Joshi's external stabilising system has a promising feature and will be an additional method to our armamentarium in the management of clubfoot.

\section{References}

1. Azar FM, Canale ST, Beaty JH. Campbell's operative orthopaedics, $13^{\text {th }}$ edition, Elsevier, Philadelphia, 2013, 1031.

2. Ponseti IV, Smoley EN. Congenital clubfoot the results of treatment. J Bone Joint Surg. 1963; 45:134-41.

3. Turco VJ. Surgical correction of the resistant club foot. One $^{-}$stage posteromedial release with internal fixation: A preliminary report. J Bone Joint Surg Am. 1971; 53:477-97.

4. Atar D, Lehman WB, Grant AD. Complications in clubfoot surgery. Orthop Rev. 1991; 20:233-9.

5. Ilizarov GA. Clinical application of the tension-stress effect for limb lengthening. Clin Orthop. 1990; 250:8-26.

6. Bradish $\mathrm{CF}$, Noor $\mathrm{S}$. The Ilizarov method in the management of relapsed club feet. J Bone Joint Surg Br. 2000; 82:387-91.

7. Wallander H, Hansson G, Tjernström B. Correction of persistent clubfoot deformities with the Ilizarov external fixator. Experience in 10 previously operated feet followed for 2-5 years. Acta Orthop Scand. 1996; 67:283-7.

8. Ferreira RC, Costa MT, Frizzo GG, Santin RA. Correction of severe recurrent clubfoot using a simplified setting of the Ilizarov device. Foot Ankle Int. 2007; 28:557-68.

9. Joshi BB, Laud NS, Warrier S, Kanaji BG, Joshi AP, Dabake H. Treatment of CTEV by Joshi's External Stabilization System (JESS). In, Kulkarni GS (ed). Textbook of Orthopaedics and Trauma, 1st edition. New Delhi, Jaypee Brothers Medical Publishers, 1999.

10. Galante VN, Molfetta L, Simone C. The treatment of clubfoot with external fixation: A review of results. Curr Orthop 1995;9:185-8

11. Suresh S, Ahmed A, Sharma VK. Role of Joshi's external stabilisation system fixator in the management of idiopathic clubfoot. J Orthop Surg (Hong Kong). 2003; 11:194-201.

12. Anwar MH, Arun B. Short term results of Correction of CTEV with JESS Distractor. J. Orthopaedics. 2004;1:e3

13. Simons GW. Complete subtalar release in club feet. Part II--Comparison with less extensive procedures. J Bone Joint Surg Am. 1985; 67(7):1056-65.

14. Oganesian OV, lstomina IS. Talipes equinocavovarus deformities corrected with the aid of a hinged-distraction apparatus. Clin Orthop. 1991; 266:42-50. 